\title{
InAs/InAsSb Strain-Balanced Superlattices for Longwave Infrared Detectors
}

\author{
Tetiana Manyk ${ }^{1, *} \mathbb{C}$, Krystian Michalczewski ${ }^{1,2}$, Krzysztof Murawski $^{1}$, Piotr Martyniuk ${ }^{1}$ and \\ Jaroslaw Rutkowski ${ }^{1}$ \\ 1 Institute of Applied Physics, Military University of Technology, 2 Urbanowicza Str., 00-908 Warsaw, Poland; \\ krystian.michalczewski@wat.edu.pl (K.M.); krzysztof.murawski01@wat.edu.pl (K.M.); \\ piotr.martyniuk@wat.edu.pl (P.M.); jaroslaw.rutkowski@wat.edu.pl (J.R.) \\ 2 VIGO System S.A. 129/133 Poznanska Str., 05-850 Ozarow Mazowiecki, Poland; \\ kmichalczewski@vigo.com.pl \\ * Correspondence: tetjana.manyk@wat.edu.pl; Tel.: +48-261-839-673
}

Received: 19 March 2019; Accepted: 20 April 2019; Published: 22 April 2019

check for updates

\begin{abstract}
The InAs/InAsSb type-II superlattices (T2SLs) grown on a GaSb buffer layer and GaAs substrates were theoretically investigated. Due to the stability at high operating temperatures, T2SLs could be used for detectors operating in the longwave infrared (LWIR) range for different sensors to include, e.g., $\mathrm{CH}_{4}$ and $\mathrm{C}_{2} \mathrm{H}_{6}$ detection, which is very relevant for health condition monitoring. The theoretical calculations were carried out by the $8 \times 8 \mathrm{k} \cdot \mathrm{p}$ method. The estimated electrons and heavy holes probability distribution in a InAs/InAsSb superlattice (SL) shows that the wave function overlap increases while the thickness of the SL period decreases. The change in the effective masses for electrons and holes versus the SL period thickness for the $\mathrm{k}_{\mathrm{z}}$-direction of the Brillouin zone is shown. The structures with a period lower than $15 \mathrm{~nm}$ are more optimal for the construction of LWIR detectors based on InAs/InAsSb SLs. The experimental results of InAs/InAsSb T2SLs energy bandgap were found to be comparable with the theoretical one. The proper fitting of theoretically calculated and experimentally measured spectral response characteristics in terms of a strain-balanced and unbalanced structures is shown.
\end{abstract}

Keywords: T2SLs InAs/InAsSb; energy bandgap; infrared detectors; LWIR

\section{Introduction}

Smith et al. [1] in 1987 proposed the use of type-II superlattices (T2SLs) InAs/GaSb as optoelectronic materials exhibiting excellent electro-optical properties, theoretically comparable to HgCdTe being the main compound for detection in the infrared radiation (IR) region [2]. In addition, Ga-free T2SLs InAs/InAs ${ }_{1-x} \mathrm{Sb}_{\mathrm{x}}$ have been proved to have a longer carrier lifetime $(\tau)$ than InAs/GaSb T2SLs [3] and have been proposed as an alternative for IR photodetectors [4]. The molecular beam epitaxy (MBE) technology development allowed investigation of the superlattices (SLs) InAs/InAsSb on a GaSb buffer layer grown on GaAs substrates. The InAs${ }_{1-x} S_{b x}$ energy bandgap $\left(E_{g}\right)$ changes non-linearly versus the $\mathrm{Sb}$ molar composition in the ternary compound. The form of this relation depends on the $\operatorname{InAs}_{1-\mathrm{x}} \mathrm{Sb}_{\mathrm{x}}$ growth method and is given in different forms by research groups [5,6].

In the InAs/InAsSb SLs due to the T2SLs band alignment the electron and hole states are confined within the InAs (electrons) and InAsSb (holes) layers, and thus electrons and holes are spatially separated. Therefore, by adjustment of the InAs and/or InAsSb thickness as well as the Sb molar composition $\left(x_{S b}\right)$, it is feasible to tune $E_{g}$ within a wide range of IR. Owing to these unique properties, T2SLs InAs/InAsSb have been chosen as materials for applications in the longwave infrared radiation (LWIR) detectors operating within the 8-15 $\mu \mathrm{m}$ range. Both photoconductive and photovoltaic 
detectors are constructed. T2SLs InAs/InAsSb are mainly used for the fabrication of barrier detectors to include nBn and pBn design $[7,8]$, low-noise interband cascade infrared photodetectors (ICIP) $[9,10]$, dual band long-wavelength infrared photodiodes [11] and very fast avalanche photodiodes (APD). These detectors can be used for a wide range of applications in the fields of science, medicine, safety, industry, and automotive, such as railway safety, gas leak detection, flame detection, heat distribution monitoring, medical diagnostic imaging, space operations, night vision devices and spectroscopy. Since humanity is facing healthcare challenges that include the rising and potentially unsustainable health and care costs, mainly due to the increasing prevalence of chronic diseases, and the influence on health of external environmental factors including climate change, there is a need to have simple devices allowing us to detect and diagnose e.g., lipid peroxidation, vitamin E deficiency, chronic respiratory disease, cells oxidative stress, or even scleroderma and cystic fibrosis. This could be allowed by e.g., the $\mathrm{C}_{2} \mathrm{H}_{6}$ level monitoring through unexplored LWIR, requiring a proper detector operating in that range. In addition, in the LWIR, the two main detrimental scattering effects of Rayleigh and Mie are significantly reduced $[12,13]$.

The T2SL system was modeled using a variety of theoretical approaches, such as the tight-binding, pseudopotential and $\mathrm{k} \cdot \mathrm{p}$ methods. The $\mathrm{k} \cdot \mathrm{p}$ method is widely used because of its proper numerical accuracy. We present a comparison of the responsivity of high operating temperature (HOT) LWIR $\operatorname{InAs} / \operatorname{InAs}_{1-x} \mathrm{Sb}_{\mathrm{x}}$ T2SLs photoconductors with simulated absorption spectra.

\section{Materials and Methods}

The theoretical calculation of band structure, $E_{g}$ and absorption coefficient $(\alpha)$ was performed using the standard k.p $(8 \times 8$ method) by the SimuApsys and nextnano platforms [14,15]. In Figure 1 , the schematic representation of the energy bands of the strained and unstrained InAs/InAsSb SL is presented.

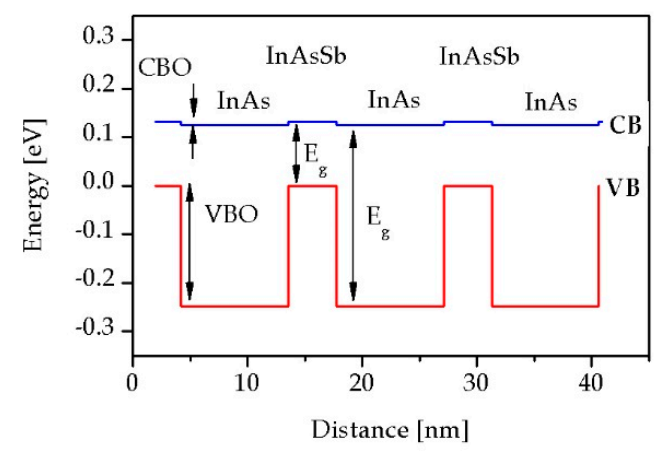

(a)

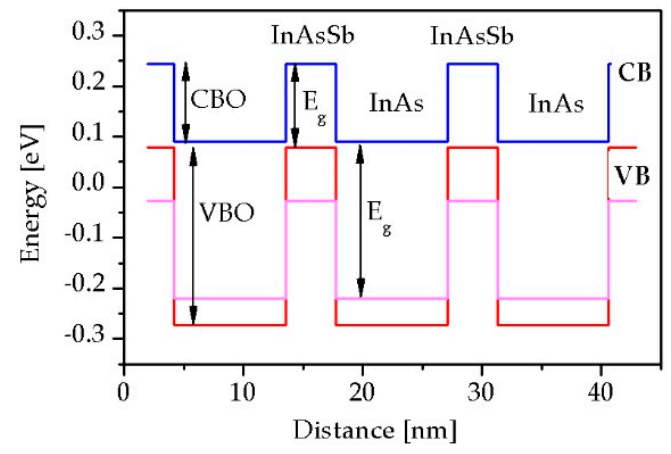

(b)

Figure 1. Schematic representation of (a) unstrained and (b) strained type-II superlattices (T2SLs) InAs/InAs ${ }_{1-x} \mathrm{Sb}_{\mathrm{x}} \mathrm{SLs}$.

Figure 1 shows that when the SL is coherently strained, all energy parameters are being changed to include conduction band offset (CBO), valence band offset (VBO) and $E_{g}$ of the InAs (InAsSb) layers. The blue line corresponds to the lowest conduction band $(\mathrm{CB})$, and the red line indicates the highest valence band (VB). If the SL lattice-match to the GaSb substrate is taken into account, the InAs and $\operatorname{InAs}_{1-x} \mathrm{Sb}_{\mathrm{x}}$ layers become strained and valence band splits to the heavy (hh) and light (lh) hole sub-bands in InAs/InAsSb SLs. In Figure 1 the violet line represents the lh subband edge in the strained SLs and the separation of the hh and $\mathrm{lh}$ bands is also visible. The change in VBO value between the state without strain and strained remains within $0.1 \mathrm{eV}$ [5].

The $\mathrm{k} \cdot \mathrm{p}(8 \times 8$ method $)$ simulation was implemented to study dispersion curves in order to estimate the SLs' effective masses. The periodic boundary conditions were used in the simulation procedure. These conditions impose periodicity on the wave functions (WF). 
The parameters of InAs, InSb and GaSb layers used in InAs/InAs $s_{1-x} S_{x}$ SLs simulation procedure are presented in Table 1. Parameters are taken from the papers of several authors [5,16-21]. $E_{g}$ versus temperature $(T)$ is given by the Varshni form: $E_{g}(T)=E_{0}-\alpha T^{2} /(T+\beta)$.

Table 1. Material parameters of InAs, InSb and GaSb layers used in simulation.

\begin{tabular}{cccc}
\hline Parameter & InAs & InSb & GaSb \\
\hline $\mathrm{E}_{0}(\Gamma)[\mathrm{eV}]$ & 0.417 & 0.235 & 0.812 \\
$\mathrm{E}_{0}(\mathrm{X})[\mathrm{eV}]$ & 1.433 & 0.63 & 1.141 \\
$\mathrm{E}_{0}(\mathrm{~L})[\mathrm{eV}]$ & 1.133 & 0.93 & 0.875 \\
$\Delta_{\mathrm{so}}[\mathrm{eV}]$ & 0.39 & 0.81 & 0.76 \\
$\mathrm{~m}_{\mathrm{e}} / \mathrm{m}_{0}(0 \mathrm{~K})$ & 0.026 & 0.014 & 0.039 \\
$\mathrm{E}_{\mathrm{V}}, \mathrm{vac}$ & 1.39 & 1.75 & 1.78 \\
$\mathrm{a}=\mathrm{f}(\mathrm{T})[\AA]$ & $6.0583+2.47 \times 10^{-5}(\mathrm{~T}-300)$ & $6.4794+3.48 \times 10^{-5}(\mathrm{~T}-300) 6.0959+4.72 \times 10^{-5}(\mathrm{~T}-300)$ \\
\hline
\end{tabular}

All parameters for ternary compounds used for simulations were estimated based on the bulk parameters for binary compounds. It should be noted that we considered the symmetrical case when the Kane parameter, $F=0$ [15]. Most parameters assumed in simulations exhibit $T$ dependence and vary linearly with $x_{S b}$. In order to calculate some $\operatorname{InAs}_{1-\mathrm{x}} \mathrm{Sb}_{\mathrm{x}}\left(0<x_{S b}<1\right)$ parameters the bowing shown in the Table 2 was used.

Table 2. Bowing parameter assumed in simulations $(T=230 \mathrm{~K})$.

\begin{tabular}{cc}
\hline Bowing Coefficient & Bowing Parameter $\left(\mathbf{b}_{\text {bow }}\right)$ \\
\hline $\mathrm{b}_{\mathrm{g}}[\mathrm{eV}]$ & 0.72 \\
$\mathrm{~b}_{\Delta \mathrm{so}}[\mathrm{eV}]$ & 1.2 \\
$\mathrm{~b}_{\mathrm{me} / \mathrm{m} 0}$ & 0.035 \\
$\mathrm{~b}_{\mathrm{v}}, \mathrm{vac}[\mathrm{eV}]$ & -0.47 \\
\hline
\end{tabular}

An equation for ternary compounds parameters, $\mathrm{Y}_{\text {InAsSb }}$ dependence on the bowing coefficient is defined as:

$$
\mathrm{Y}_{\text {InAsSb }}=\left(1-\mathrm{x}_{\mathrm{Sb}}\right) \times \mathrm{Y}_{\text {InAs }}+\mathrm{x}_{\mathrm{Sb}} \times \mathrm{Y}_{\text {InSb }}-\mathrm{b}_{\mathrm{bow}} \times \mathrm{x}_{\mathrm{Sb}} \times\left(1-\mathrm{x}_{\mathrm{Sb}}\right) .
$$

The Luttinger parameters have been estimated based on respective effective masses according to equations presented by Birner et al. [15] and Vurgaftman et al. [16]. The VBO was determined by the following equation:

$$
\mathrm{VBO}=\mathrm{E}_{\mathrm{V}, \mathrm{vac}(\operatorname{InAs})}-\left[\mathrm{E}_{\mathrm{V}, \mathrm{vac}(\operatorname{InAs})} \times\left(1-\mathrm{x}_{\mathrm{Sb}}\right)+\mathrm{E}_{\mathrm{v}, \mathrm{vac}(\operatorname{InSb})} \times\left(\mathrm{x}_{\mathrm{Sb}}\right)-\mathrm{x}_{\mathrm{Sb}} \times \mathrm{b}_{\mathrm{v}, \mathrm{vac}} \times\left(1-\mathrm{x}_{\mathrm{Sb}}\right)\right],
$$

where the vacuum energy levels of the valence band $\left(\mathrm{E}_{\mathrm{v}}, \mathrm{vac}\right)$ and the valence band bowing parameter $\left(b_{\mathrm{v}}\right.$, vac $)$ were presented in Tables 1 and 2 , respectively.

All calculated SL structures are strain-balanced on GaSb. The strain-balanced condition is reached by setting the average lattice parameter of one period weighted with the layer thickness being equal to the lattice constant of $\mathrm{GaSb}$. The InAs $\mathrm{As}_{1-\mathrm{x}} \mathrm{Sb}_{\mathrm{x}}$ layer thickness $\left(\mathrm{d}_{\mathrm{In} A s S b}\right)$ versus $x_{S b}$, lattice constant $\left(\mathrm{a}_{\mathrm{InAs}(\mathrm{InSb}, \mathrm{GaSb})}\right)$ and SL period $(L)$ can be calculated from Equation [22]:

$$
\mathrm{d}_{\mathrm{InAsSb}}=\left(\frac{\mathrm{a}_{\mathrm{GaSb}}-\mathrm{a}_{\mathrm{InAs}}}{\mathrm{a}_{\mathrm{InSb}}-\mathrm{a}_{\operatorname{InAs}}}\right) \times \frac{\mathrm{L}}{x_{\mathrm{Sb}}} .
$$

The lattice constant at $300 \mathrm{~K}$ is presented in Table 1. The thickness of the InAsSb layer in InAs/InAsSb SL structures was determined by relation (3) giving the thickness of the layer being compensated to zero sum of the strains of all constituent SL layers. 


\section{Results and Discussion}

\subsection{Influence of the Period on the Superlattice (SL) Parameters}

Figure 2 shows the lowest transition energy ( $E_{g}$-between the first level of $C B \mathrm{e}_{1}$ and $\left.V B h_{1}\right)$ versus $x_{S b}$ in InAsSb for SL periods between $10 \mathrm{~nm}$ and $40 \mathrm{~nm}$ at $T=230 \mathrm{~K}$.

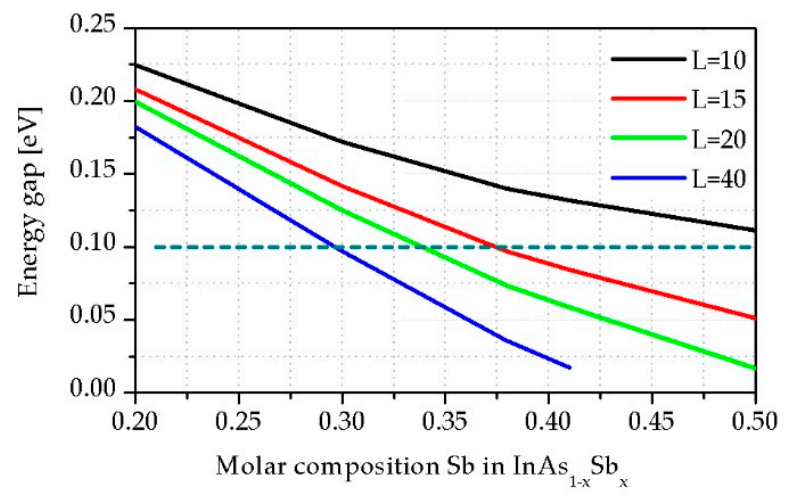

Figure 2. Theoretically simulated $E_{g}$ for the InAs/InAsSb strain balanced superlattice (SL) structures versus $x_{S b}$ at $T=230 \mathrm{~K}$.

Figure 2 depicts that it is possible to reach the desired $E_{g}$ by changes in both $x_{S b}$ and L. When $x_{S b}$ and $L$ increase, $E_{g}$ decreases.

The broken line in Figure 2 indicates an energy equal of $0.1 \mathrm{eV}$, which allows us to compare the difference between the thickness for the InAs/InAsSb strain-balanced SL structures with the same $E_{g}$. The absorption coefficient presented in Figure 3 was calculated by the commercial SimuApsys platform according to the method presented in [23] for selected points from this line with another SL period.

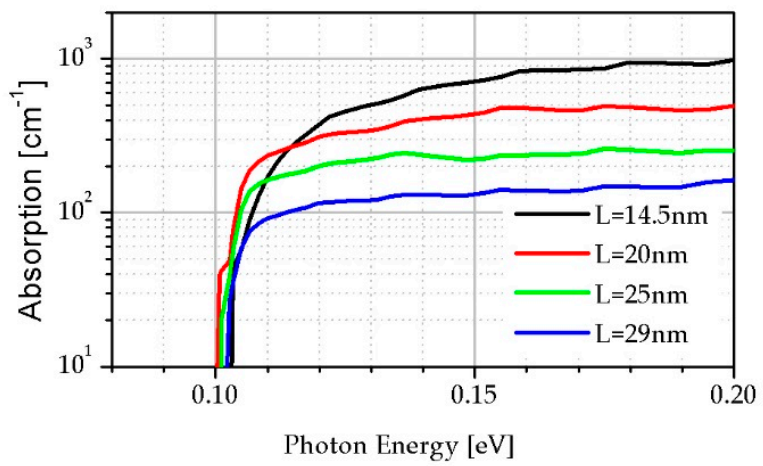

Figure 3. $\alpha$ theoretical simulation versus photon energy for the strain-balanced SL InAs/InAsSb.

Figure 3 shows that $\alpha$ near the edge of absorption decreases when thickness of the InAs/InAsSb SL increases, being connected with the overlap of the electrons and holes WF in InAs/InAsSb SL.

The probability distribution for electrons and heavy holes in InAsSb/InAs SLs is presented in Figure 4. These simulations are at $T=230 \mathrm{~K}$ for $x_{S b}=0.38$ and SL period $L=12 \mathrm{~nm}, 20 \mathrm{~nm}$ and $29 \mathrm{~nm}$, respectively. The heavy hole WF is strongly localized within the InAsSb barrier region but electron WF spreads out through the structure with significant probability of residing in the InAs quantum well (QW) region. Figure 4 shows that if the period of the InAs/InAsSb strain-balanced SL increases the overlap of the electrons and holes, WF decreases. The values of the overlap are $21.4 \%, 14.8 \%, 8.7 \%$ for the SL period $L=12 \mathrm{~nm}, 20 \mathrm{~nm}, 29 \mathrm{~nm}$, respectively. The decrease in overlap confirms the reduction of $\alpha$ when SL period increases. 


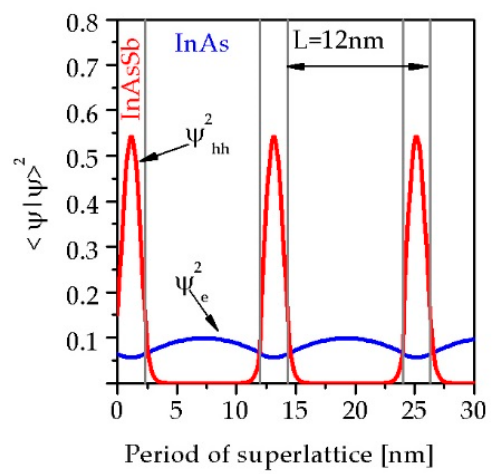

(a)

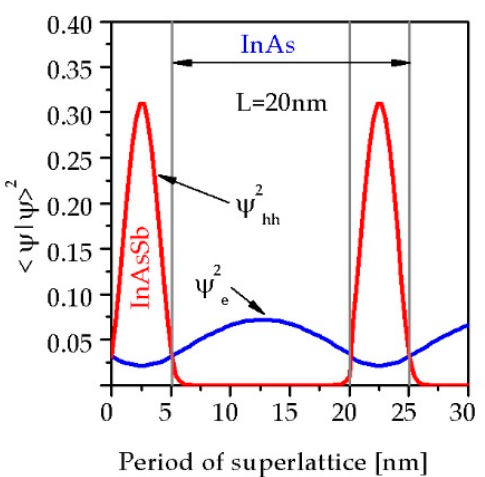

(b)

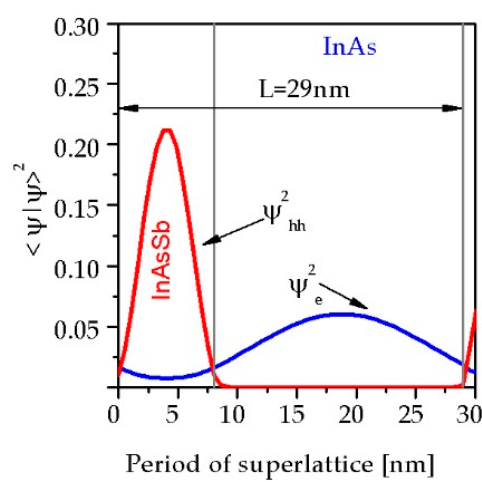

(c)

Figure 4. Electrons and heavy holes probability distribution for InAs/InAsSb SL structures at $230 \mathrm{~K}$ for the SL period: (a) $12 \mathrm{~nm}$; (b) $20 \mathrm{~nm}$; (c) $29 \mathrm{~nm}$.

Thin period InAs/InAsSb SL structures shows that better optical properties and thinner layers in SL are more stable in terms of the electrons and holes interaction in deeper energy levels. As can be seen from Figure 5, when the period of SL is above $15 \mathrm{~nm}$, the position of $\mathrm{lh}$ and hh sub-bands is changed affecting on $\alpha$. In SL with a period exceeding $30 \mathrm{~nm}$ three bands of heavy holes: $\mathrm{hh}_{1}, \mathrm{hh}_{2}$ and $\mathrm{hh}_{3}$ lies above the light hole sub-band $\mathrm{lh}_{1}$.

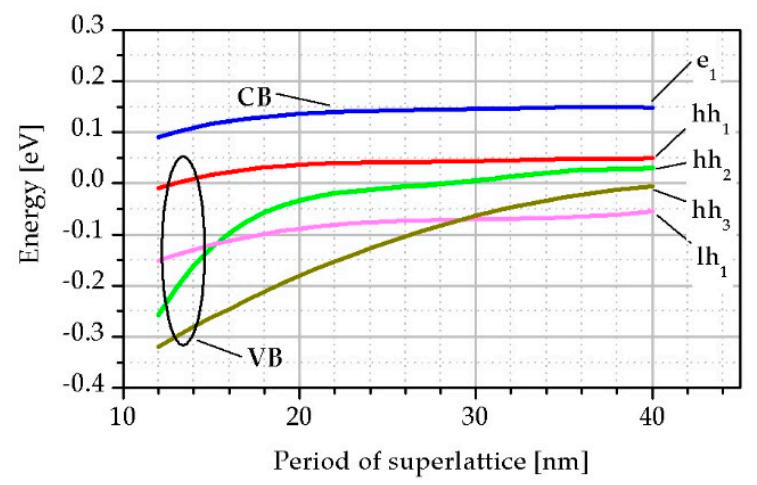

Figure 5. The $\mathrm{CB} \mathrm{e}_{1}$ and VB: $\mathrm{hh} \mathrm{h}_{1}, \mathrm{~h} \mathrm{~h}_{2}, \mathrm{hh}_{3}, \mathrm{lh}_{1}$ positions versus SL period.

The electrons and holes effective masses were calculated from the dispersion curves as the second derivative of energy by the wave vector (k). For directions in the $\mathrm{k}_{\mathrm{x}}, \mathrm{k}_{\mathrm{y}}$ of the Brillouin zone effective masses hardly change with the SL period but for direction $k_{z}$ dependence of the effective masses versus SL period is significant (see Figure 6). When $x_{S b}$ increases the hh effective masses decreases while both $\mathrm{lh}$ and $\mathrm{e}_{1}$ masses increase. It can be seen that an increase in the InAs/InAsSb SL period leads to more significant change in the $\mathrm{lh}_{1}$ mass. Moreover, it should be noted that with a change in the SL period in the range of $10-20 \mathrm{~nm}$, the $\mathrm{lh}$ mass slowly increases and stays constant to $0.1 \mathrm{~m}_{0}$ while with a further increase in SL period those masses increase and become similar to the hh masses.

In the case of T2SLs InAs/InAs ${ }_{0.62} \mathrm{Sb}_{0.38}$ with the $L=14.5 \mathrm{~nm}$ at $T=230 \mathrm{~K}$, the calculated effective masses of $\mathrm{e}_{1}$, hh and $\mathrm{lh}$ for directions in the $\mathrm{k}_{\mathrm{x}}, \mathrm{k}_{\mathrm{y}}(\|)$ and $\mathrm{k}_{\mathrm{z}}(\perp)$ of the Brillouin zone are: $\mathrm{m}_{\mathrm{e} \|}^{*}=$ $0.019 \mathrm{~m}_{0}, \mathrm{~m}_{\mathrm{e} \perp}^{*}=0.023 \mathrm{~m}_{0}, \mathrm{~m}_{\mathrm{hh} \|}^{*}=0.040 \mathrm{~m}_{0}, \mathrm{~m}_{\mathrm{hh} \perp}^{*}=31.02 \mathrm{~m}_{0}, \mathrm{~m}_{\mathrm{lh} \|}^{*}=0.104 \mathrm{~m}_{0}, \mathrm{~m}_{\mathrm{lh} \perp}^{*}=0.096 \mathrm{~m}_{0}$. 


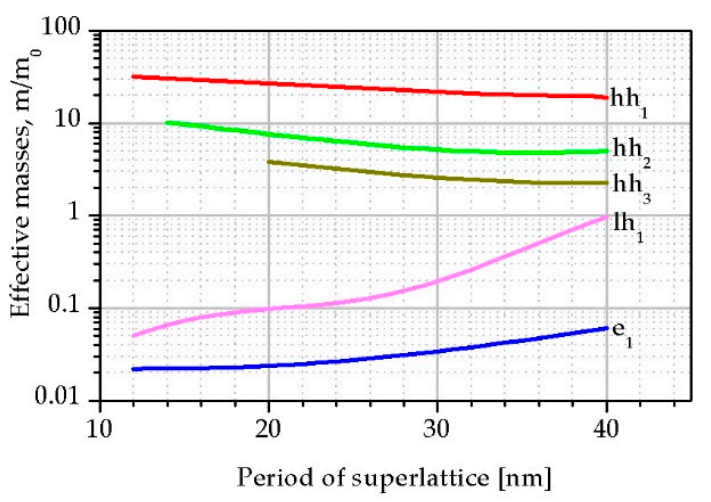

Figure 6. The calculated $\mathrm{e}_{1}$ and $\mathrm{hh}_{1}, \mathrm{hh}_{2}, \mathrm{hh}_{3}$ and $\mathrm{lh}_{1}$ effective masses for the $\mathrm{k}_{\mathrm{z}}$-direction of the Brillouin zone versus SL period.

In order to explain the shape of the absorption curves in a wider photon energy range, it is necessary to consider the polarization of the light [24]. Figure 7 shows $\alpha$ for both transverse electronic (TE) and transverse magnetic (TM) mode in the LWIR region for two different SL periods equal to $L=14.5 \mathrm{~nm}$ and $L=25 \mathrm{~nm}$. These theoretical calculations show four prominent transition channels, namely $\mathrm{e}_{1}-\mathrm{hh}_{1}, \mathrm{e}_{1}-\mathrm{hh}_{2}, \mathrm{e}_{1}-\mathrm{hh}_{3}$ and $\mathrm{e}_{1}-\mathrm{lh}_{1}$ contributing to the TE and TM absorption in this wavelength region. The absorption strength for TE is higher than that for TM polarization.

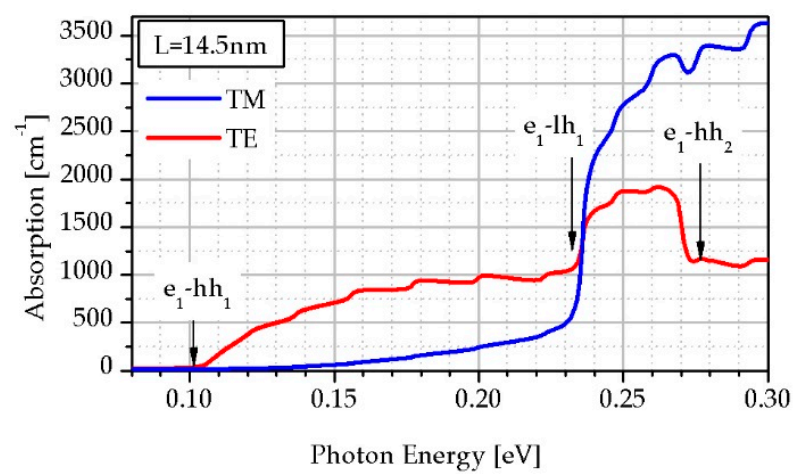

(a)

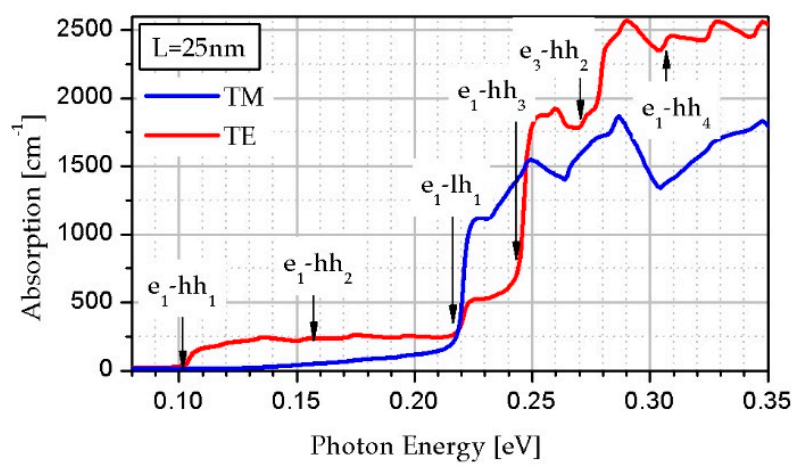

(b)

Figure 7. The polarization-dependent transverse electronic (TE) and transverse magnetic (TM) $\alpha$ versus energy in InAs/InAs ${ }_{0.62} \mathrm{Sb}_{0.32}$ SL structures at $230 \mathrm{~K}$ for the SL period equal to: (a) $14.5 \mathrm{~nm}$, (b) $25 \mathrm{~nm}$.

The transition probability is proportional to the square of the optical matrix element per period. Figure 8 presents the optical matrix elements for the $\mathrm{e}_{1}-\mathrm{hh}_{1}, \mathrm{e}_{1}-\mathrm{hh}_{2}, \mathrm{e}_{1}-\mathrm{hh}_{3}$ and $\mathrm{e}_{1}-\mathrm{lh}_{1}$ transition for the TE and TM polarization for the InAs/InAs $s_{0.62} \mathrm{Sb}_{0.32}$ strain-balanced SL with the $L=25 \mathrm{~nm}$ at $T=230 \mathrm{~K}$. The optical matrix element for the $\mathrm{e}_{1}-\mathrm{hh}_{1}$ transition is larger for TE polarization than for TM. In turn, 
the TE-polarized absorption increases sharply near $E_{g}$ due to the $\mathrm{e}_{1}-\mathrm{hh}_{1}$ transition, while the TM absorption increases markedly at higher energies due to $\mathrm{e}_{1}-\mathrm{lh}_{1}$ transition. Figure 8 shows that the optical matrix element $\mathrm{e}_{1}-\mathrm{hh} \mathrm{h}_{2}$ has no effect on the coefficient $\alpha$, since its value is almost zero.

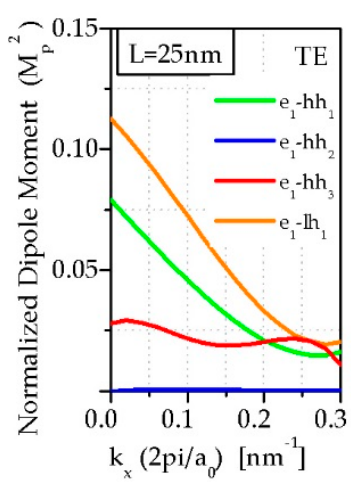

(a)

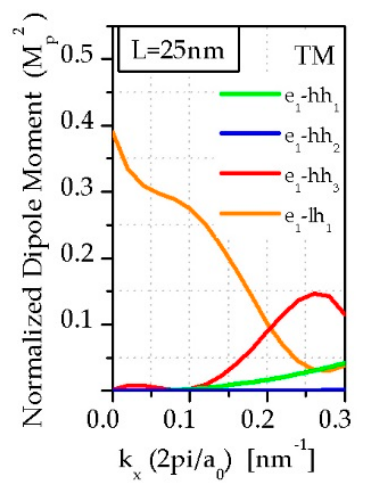

(b)

Figure 8. (a) TE and (b) TM-polarized the optical matrix for the InAs/InAs ${ }_{0.62} \mathrm{Sb}_{0.32}$ strain balanced SL for $L=25 \mathrm{~nm}$ at $T=230 \mathrm{~K}$.

Typical spectra contains two main features where one is an increase of absorption $\left(\mathrm{e}_{1}-\mathrm{hh}_{1}\right)$ while the second one is a peak at higher energy corresponding to the transition between other bands. From the theoretical descriptions presented above, it follows that two transitions have a great influence on $\alpha$, namely $\mathrm{e}_{1}-\mathrm{hh}_{1}$ and $\mathrm{e}_{1}-\mathrm{lh}_{1}$ (see Figure 7).

\subsection{Comparison of the Theoretical Simulation with the Experimental Data}

The T2SLs InAs/InAsSb were grown on GaAs substrates by a RIBER Compact 21-DZ solid-source MBE system. A $1.2 \mu \mathrm{m}$-thick GaSb layer was grown to reduce the large lattice mismatch between GaAs substrate and the SLs. Then, 300 periods 34.3 ML InAs/9 ML InAsSb SLs were deposited. Growth details of InAs/InAsSb SL are reported in the paper by Michalczewski et al. [25]. After the growth, photolithography-assisted wet-etching was used to define the active and contact areas of the IR photoconductors. The vacuum evaporation of $\mathrm{Au} / \mathrm{Ti}$ was applied to fabricate ohmic contacts.

In order to obtain a proper agreement between theoretical calculations and experimental data, the temperature-dependent bowing parameter for $E_{g}$ was used. In our simulation the bowing parameter decreases versus $T$ assuming $0.67 \mathrm{meV}$ at $300 \mathrm{~K}$. Figure 9 shows the theoretical simulation and experimental data of $\alpha$ for $1.7 \mu \mathrm{m}$ thick T2SLs InAs/InAs ${ }_{0.62} \mathrm{Sb}_{0.38}$ with $L=13.2 \mathrm{~nm}$ SL at $300 \mathrm{~K}$. We have reached proper agreement between the experimental data and theoretical simulation. Figure 9 shows the transition $\mathrm{e}_{1}-\mathrm{hh}_{1}$ being equal to $E_{g}$ and the second one corresponds to $\mathrm{e}_{1}-\mathrm{lh}_{1}$ transition.

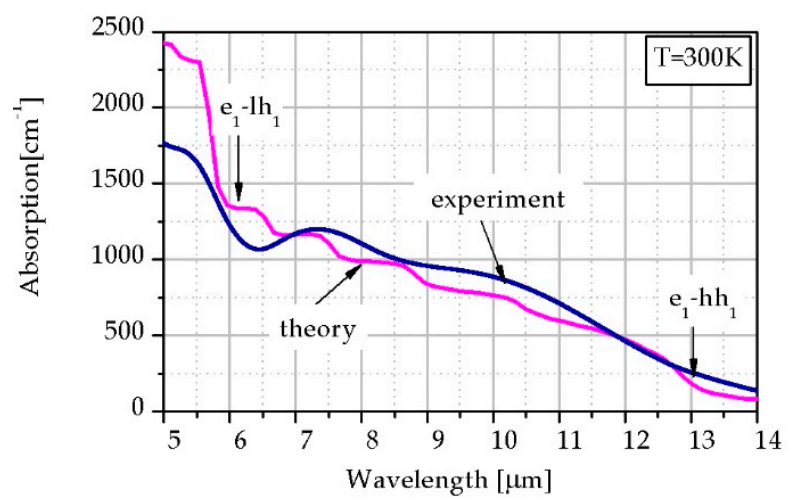

Figure 9. $\alpha$ theoretical simulation and experimental data for T2SLs InAs/InAs ${ }_{0.62} \mathrm{Sb}_{0.38}$ with $L=13.2 \mathrm{~nm}$ at $T=300 \mathrm{~K}$. 
T2SLs photoconductor spectral current responsivity $\left(R_{i}\right)$ operating in LWIR range at bias $0.5 \mathrm{~V}$ and $T=230 \mathrm{~K}$ was measured and results are presented in Figure 10 where green line depicts theoretical fitting while pink stars correspond to the experimental results for two samples, A and B. The SL period, the thickness InAs and InAs $s_{1-x} S_{b}, x_{S b}, E_{g}$ and the fitting $\tau$ are presented in Table 3.

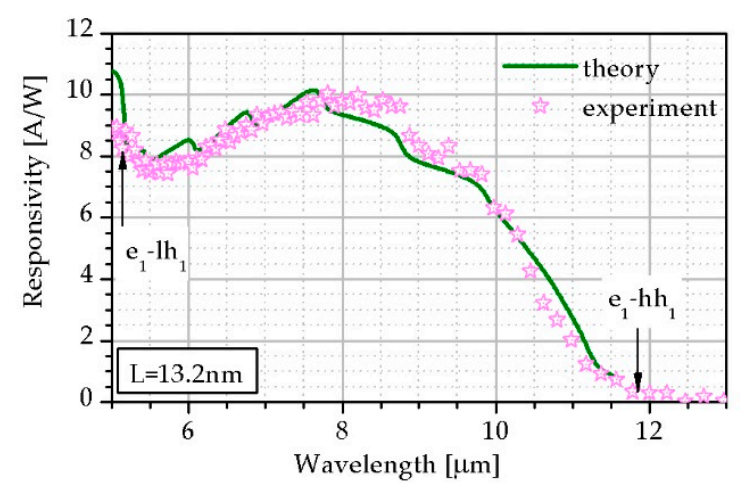

(a)

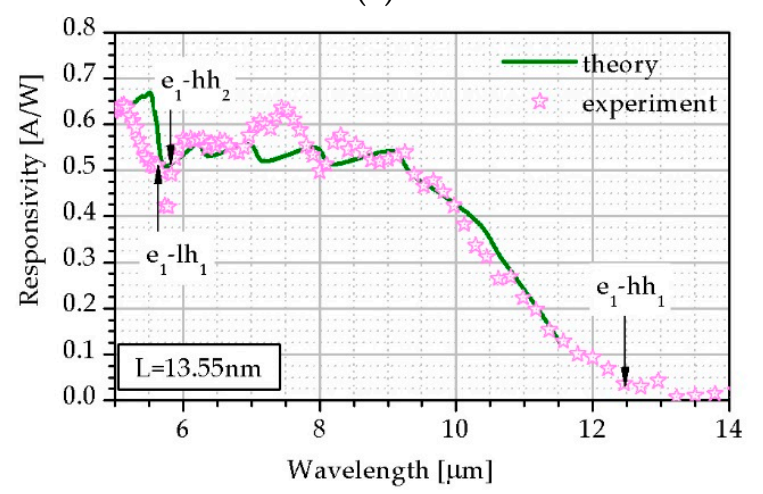

(b)

Figure 10. $R_{i}$ theoretical simulation and experimental results for T2SLs InAs/InAs $\mathrm{As}_{0.62} \mathrm{Sb}_{0.38}$ photoconductor for (a) sample-A; (b) sample-B at $T=230 \mathrm{~K}$.

Table 3. The sample-A and sample-B parameters.

\begin{tabular}{ccccccc}
\hline Sample & $\boldsymbol{L}[\mathbf{n m}]$ & $\boldsymbol{L}_{\text {InAsSb }}[\mathbf{n m}]$ & $\boldsymbol{L}_{\text {InAs }}[\mathrm{nm}]$ & $\boldsymbol{x}_{\boldsymbol{S b}}$ & $\boldsymbol{E}_{\boldsymbol{g}}[\mathrm{eV}]$ & $\boldsymbol{\tau}$ [ns] \\
\hline A & 13.20 & 2.8 & 10.4 & 0.38 & 0.1048 & 24 \\
B & 13.55 & 4.2 & 9.35 & 0.38 & 0.0996 & 1.2 \\
\hline
\end{tabular}

In the case of theoretical calculations the $R_{i}$ was estimated by $\alpha$ and $\tau$ fitting. Theoretical calculations exhibit proper coincidence with experimental data.

Figure 10 shows a comparison of $R_{i}$ theoretical simulation and experimental results for the two samples. Their common feature is the same composition $\left(x_{S b}=0.38\right)$ while the difference is the thickness of the SLs (the ratio of the thicknesses InAs and InAsSb) and $E_{g}$. Figure 10 a corresponds to sample-A where thickness is located in the strain-balanced region while Figure $10 \mathrm{~b}$ depicts sample-B exhibiting unbalanced strain structure. The fitting to experimental results was performed by $\tau$. Table 3 indicates that $\tau$ for sample-B is much lower than for sample-A explaining the difference in $R_{i}$. We believe that the structure by which the responsivity is presented in Figure 10a is optimally balanced. Thus, the optimal structure of T2SLs InAs/InAsSb for LWIR photodetectors should have an strain-balanced absorber with the following parameters: SL period of $12 \mathrm{~nm}<\mathrm{L}<15 \mathrm{~nm}$ and Sb molar composition in $\operatorname{InAs}_{1-\mathrm{x}} \mathrm{Sb}_{\mathrm{x}}$ of $0.37<x<0.45$. 


\section{Conclusions}

The T2SLs InAs/InAs ${ }_{1-x} \mathrm{Sb}_{\mathrm{x}}$ SLs on a GaSb buffer and GaAs substrate were investigated. The use of InAs/InAs ${ }_{1-x} \mathrm{Sb}_{\mathrm{x}} \mathrm{SLs}$ gives a great opportunity to fabricate devices for IR radiation detection in a wide wave range by selecting the SL period and the Sb molar composition of the $\operatorname{InAs}_{1-x} \mathrm{Sb}_{\mathrm{x}}$ barrier. In the calculations, the thickness of the InAsSb barrier for the given period was assumed to ensure a strain balanced SLs. The paper shows that the reduction in period thickness and increase in Sb molar composition in the InAsSb barrier allows higher absorption to be reached for the same absorption edge. An absorption improvement is caused by the increase of the electrons and holes wave function overlap due to the thinner and lower InAsSb barrier. With the change in the thickness of the SL period, the position of the light and heavy hole bands changes significantly. With a period smaller than $15 \mathrm{~nm}$, the light holes band is located directly under the heavy holes band, while for periods larger than $30 \mathrm{~nm}$ it is separated from the conduction band by three heavy holes bands. Numerical simulations show that the position of the light holes sub-band directly below the first heavy holes sub-band increases the probability of optical transitions, hence structures with a smaller period are more optimal for the construction of LWIR detectors based on InAs/InAsSb SLs.

The experimental data were compared with the results of numerical simulations, showing proper agreement by lifetime fitting. The estimated carrier lifetime for a balanced structure is more than an order of magnitude higher than for a non-balanced one indicating that the generation of a large number of defects in the unbalanced structure increases the recombination rate of carriers reducing the carrier lifetime and current responsivity.

Author Contributions: Conceptualization, T.M.; Methodology, T.M.; Formal Analysis, J.R.; Investigation, K.M. (Krystian Michalczewski) and K.M. (Krzysztof Murawski); Writing-Original Draft Preparation, T.M.; Writing-Review \& Editing, P.M. and J.R. and T.M.; Project Administration, P.M.

Funding: This research was funded by grant number TECHMATSTRATEG1/347751/5/NCBR/2017.

Conflicts of Interest: The authors declare no conflict of interest.

\section{References}

1. Smith, L.D.; Mailhiot, C. Proposal for strained type II superlattice infrared detectors. J. Appl. Phys. 1987, 62, 2545-2548. [CrossRef]

2. Rogalski, A.; Martyniuk, P.; Kopytko, M. InAs/GaSb type-II superlattice infrared detectors: Future prospect. Appl. Phys. Rev. 2017, 4, 031304. [CrossRef]

3. Steenbergen, E.H.; Connelly, B.C.; Metcalfe, G.D.; Shen, H.; Wraback, M.; Lubyshev, D.; Qiu, Y.; Fastenau, J.M.; Liu, A.W.K.; Elhamri, S.; et al. Significantly improved minority carrier lifetime observed in a long-wavelength infrared III-V type-II superlattice comprised of InAs/InAsSb. Appl. Phys. Lett. 2011, 99, 251110. [CrossRef]

4. Rogalski, A.; Kopytko, M.; Martyniuk, P. Antimonide-Based Infrared Detectors: A New Perspective; SPIE Press: Bellingham, WA, USA, 2018.

5. Webster, P.T.; Riordan, N.A.; Liu, S.; Steenbergen, E.H.; Synowicki, R.A.; Zhang, Y.-H.; Johnson, S.R. Measurement of InAsSb bandgap energy and InAs/InAsSb band edge positions using spectroscopic ellipsometry and photoluminescence spectroscopy. J. Appl. Phys. 2015, 118, 245706. [CrossRef]

6. Svensson, S.P.; Sarney, W.L.; Hier, H.; Lin, Y.; Wang, D.; Donetsky, D.; Shterengas, L.; Kipshidze, G.; Belenky, G. Band gap of InAs ${ }_{1-x} \mathrm{Sb}_{\mathrm{x}}$ with native lattice constant. Phys. Rev. B 2012, 86, 245205. [CrossRef]

7. Kim, H.S.; Cellek, O.O.; Lin, Z.-Y.; He, Z.-Y.; Zhao, X.-H.; Liu, S.; Li, H.; Zhang, Y.-H. Long-wave infrared nBn photodetectors based on InAs/InAsSb type-II superlattices. Appl. Phys. Lett. 2012, 101, 161114. [CrossRef]

8. Haddadi, A.; Chen, G.; Chevallier, R.; Hoang, A.M.; Razeghi, M. InAs/InAs ${ }_{1-x} \mathrm{Sb}_{\mathrm{x}}$ type-II superlattices for high performance long wavelength infrared detection. Appl. Phys. Lett. 2014, 105, 121104. [CrossRef]

9. Lotfi, H.; Li, L.; Ye, H.; Hinkey, R.T.; Lei, L.; Yang, R.Q.; Keay, J.C.; Mishima, T.D.; Santos, M.B.; Johnson, M.B. Interband cascade infrared photodetectors with long and very-long cutoff wavelengths. Infrared Phys. Technol. 2015, 70, 162-167. [CrossRef] 
10. Lei, L.; Lia, L.; Yea, H.; Lotfia, H.; Yang, R.Q.; Johnsonc, M.B.; Massengalea, J.A.; Mishimab, T.D.; Santosb, M.B. Long-wavelength interband cascade infrared photodetectors towards high temperature operation. In Proceedings of the SPIE OPTO, the Optoelectronics and Photonic Materials and Devices Conference, San Francisco, CA, USA, 28 January-2 February 2017; p. 1011113.

11. Haddadi, A.; Dehzangi, A.; Chevallier, R.; Adhikary, R.; Razeghi, M. Bias-selectable nBn dual-band long-/very long-wavelength infrared photodetectors based on $\mathrm{InAs} / \mathrm{InAs}_{1-\mathrm{x}} \mathrm{Sb}_{\mathrm{x}} / \mathrm{AlAs}_{1-\mathrm{x}} \mathrm{Sb}_{\mathrm{x}}$ type-II superlattices. Sci. Rep. 2017, 7, 3379. [CrossRef] [PubMed]

12. Wojtas, J.; Gluszek, A.; Hudzikowski, A.; Tittel, K.F. Mid-infrared trace gas sensors technology based on intracavity quartz-enhanced photoacustic spectroscopy. Sensors 2017, 17, 513. [CrossRef] [PubMed]

13. Bielecki, Z.; Stacewicz, T.; Wojtas, J.; Mikołajczyk, J.; Szabra, D.; Prokopiuk, A. Selected optoelectronic sensors in medical applications. Opto-Electron. Rev. 2018, 26, 122-133. [CrossRef]

14. Lestrade, M.; Li, Z.Q.; Li, Z.S. Finite difference k.p modeling of type II MQWs. Opt. Quantum Electron. 2014, 46, 1345-1352. [CrossRef]

15. Birner, S. Modeling of semiconductor nanostructures and semiconductor-electrolyte interfaces. Available online: https://inis.iaea.org/search/search.aspx?orig_q=RN:43026032 (accessed on 21 April 2019).

16. Vurgaftman, I.; Meyer, J.R.; Ram-Mohan, L.R. Band parameters for III-V compound semiconductors and their alloys. J. Appl. Phys. 2001, 89, 5815-5875. [CrossRef]

17. Wei, S.-H.; Zunger, A. Calculated natural band offsets of all II-VI and III-V semiconductors: Chemical trends and the role of cation $d$ orbitals. Appl. Phys. Lett. 1998, 72, 2011-2013. [CrossRef]

18. Yu, P.Y.; Cardona, M. Fundamentals of Semiconductors: Physics and Materials Properties, 4th ed.; Springer: Berlin, Germany, 2010.

19. Steenbergen, E.H. Strain-balanced InAs-InAsSb Type-II Superlattices on GaSb Substrates for Infrared Photodetector Applications. Ph.D. Thesis, Arizona state university, Tempe, AZ, USA, May 2012.

20. Harrison, J.W.; Hauser, J.R. Alloy scattering in ternary III-V compounds. Phys. Rev. B 1976, 13, 5347-5350. [CrossRef]

21. Manyk, T.; Michalczewski, K.; Murawski, K.; Grodecki, K.; Rutkowski, J.; Martyniuk, P. Electronic band structure of InAs/InAsSb type-II superlattice for HOT LWIR detectors. Results Phys. 2018, 11, 1119-1123. [CrossRef]

22. Lackner, D.; Steger, M.; Thewalt, M.L.W.; Pitts, O.J.; Cherng, Y.T.; Watkins, S.P.; Plis, E.; Krishna, S. InAs/InAsSb strain balanced superlattices for optical detectors: Material properties and energy band simulations. J. Appl. Phys. 2012, 111, 034507. [CrossRef]

23. Chuang, S.L. Physics of Optoelectronics Devises; Wiley-Interscience publication: Hoboken, NJ, USA, 1995; p. 716.

24. Dong, H.M.; Li, L.L.; Xu, W.; Han, K. Effect of microscopic interface asymmetry on optical properties of short-period InAs/GaSb type-II superlattices. Thin Solid Film. 2015, 589, 388-395. [CrossRef]

25. Michalczewski, K.; Kubiszyn, .; Martyniuk, P.; Wu, C.H.; Jureńczyk, J.; Grodecki, K.; Benyahia, D.; Rogalski, A.; Piotrowski, J. Demonstration of HOT LWIR T2SLs InAs/InAsSb photodetectors grown on GaAs substrate. Infrared Phys. Technol. 2018, 95, 222-226. [CrossRef]

(C) 2019 by the authors. Licensee MDPI, Basel, Switzerland. This article is an open access article distributed under the terms and conditions of the Creative Commons Attribution (CC BY) license (http://creativecommons.org/licenses/by/4.0/). 